\title{
The Therapeutic Compliance With Athletes And Non-Athletes With Hepatitis C A Comparative Study
}

\author{
By \\ Dr. Jihan Mahmoud Yahya \\ Assistant Professor, Health's Science Department \\ - Faculty of Physical Education for Girls \\ Zagazig University \\ Egypt
}

\section{Abstract}

The research aims to identify the level of health commitment between athletes and nonathletes patients Hepatitis Virus C, Differences in health commitment between athletes and non-athletes patients Hepatitis virus $\mathrm{C}$, The researcher used the descriptive method to a sample of (74) patients Of HIV patients group (C) (40) patients exercise of moderate physical activity, (34) the patient is not practiced sports Who are undergoing treatment in Viral Hepatitis Center Al Ahrar Hospital under the Ministry of Health in Zagazig, Also subject under the medical supervision, at Zagazig University Sidnawy Hospital. By professors of the Faculty of Medicine University, who disclose these patients and follow up on their health, the researcher used the healthy commitment questionnaire, its prepared by the researcher as a tool to gather data for this research. The most important results, indicate an increase in the level of healthy commitment for patients of research sample, there are statically significant differences in Healthy commitment between athletes and non-athletes, who are patients Hepatitis virus (HCV), in favor of the athletes patients.

Key words: (Healthy Commitment, sporting, Hepatitis C virus). 


\section{Introduction:-}

Health Promotion Idea Begins from the general philosophy that, good health is the result of personal accomplishment cumulative. at the individual level, to include the development of healthy habits System, at an early stage in the life of the individual, and preserved in the two phases, adulthood and aging. On the medical level, it educating people how to access to a healthy lifestyle, Help the most liable categories of certain health risks, to behave in a way that make them to pay attention for what they can be exposed to such risks, (Maddux et al., p. 1986). Health promotion includes the availability of information to help people to develop healthy system, and maintain it, Availability of sources and methods, which help people to change harmful habits to health, through educational programs, which show people the dangers of doing certain behaviors, (Taylor, E Shelley., 2008).

Sports are closely related to the individual and community health, it cannot be conceived of a society with its members have a good health, and wellness. Only if the sports are behavior and obvious in it. Its members practiced sports continuously, and regularly according to scientific foundations and educational for sports, (Hani Haggr, Mahmoud Ismail, 2014).

The resulting health effects, from the regular practice of physical activity can be divided into three main aspects, the first aspect is to improve the functions of many organs of the body and raising their efficiency, Including the following systems: circulatory system, respiratory system, digestive system, hormonal system, nervous system, and muscular system, the second aspect is Positives of regular physical practicing, is represented in the prevention of certain diseases and health problems, Especially chronic ones, Such as coronary heart disease, diabetes, osteoporosis, colon cancer. Finally, the third aspect is the positive effects of physical activity to increase the energy discharged by the body. And therefore contribute effectively, in the prevention of obesity, and disposal from it. (Bassuk, S., Manson, J, 2003) (Fletcher, G., et al, 1996) (Grundy, S., et al, 1999) (Haskell, W, 1994) (Pate, R., et al, 1995) (Pescatello, S., et al, 2004) (Pollock, M., et al, 1998).

The rapid spread of chronic diseases, the psychological, social, and economic burden. To care for the infected people, it led to the attention of researchers about active variables in the health behavior of chronic patient. (Wild, S., et al, 2004)

The infection with chronic hepatitis $\mathrm{C}$ is a growing public health problem, although nearly 180 million people, or nearly $3 \%$ of the world's population is currently infected with this infection, the greatest burden of the disease is located in developing countries, the highest prevalence registered in Egypt amounted to $22 \%$.

In light of the foregoing, the need to improve availability to care and treatment of infected people with chronic hepatitis $\mathrm{C}$ has got increased attention. (Hadigan C, Kottilil S. Hepatitis C, 2011) (Shepard CW, Finelli L, Alter MJ., 2005) (w.h.o)

\section{http://www.who.int/bulletin/volumes/90/7/} 11-097147/ar/

Most chronic diseases require constant treatment, medical follow-up continuously, impose restrictions on the activity to control the situation or to prevent complications, However, most of the patients who suffer from a chronic disease fail to follow the recommendations prescribed them, that's exposing them to danger, And neglect of taking medications, as prescribed, or engage in behaviors that are likely to cause complications, can affect the medical diagnosis, The functional abilities of the patient, and 
behaviors that relate to follow the therapy, which aims to control the symptoms of the disease, Or prevent complications and prevent the progression of the disease is important behaviors just like the treatment itself, The commitment is one of these behaviors. (Donna R., Falvo, 2005).

Man has alerted since ancient times to the role of healthy life habits, such as those relating to the behaviors arranging, like (Eat, sleep, practice sports and physical activity time), In personal health. modern scientific studies and researches almost confirms, which dealt with the relationship between behavior and health, that this old premise is true where the focus was on the role of behavioral variables in the incidence of chronic diseases and its spread, (Moftahh Mohamed Abdelaziz 2010).

The role of the health behavior in chronic diseases, It became the main point of attempts to interfere in order to change destructive behavior and improve the quality of life for patients, (Colleen, A. et al. , 2000).

\section{And health behavior change leads to: -}

- Reduce mortality rate associated with chronic disease, by influencing the lifestyle.

- increasing assumed age, and to reduce the proportion of these diseases.

- rising time that the individual enjoys the age with health, wellness, and happiness. Far from the complications of disease, its suffering, and pain.

- Reduce the expenses of the disease at the individual and community level.

This is what poses the most difficult problems facing the patient and whose charge his health care, in other words the healthy commitment, through compliance with the doctor's instructions and follow the proper diet. So the healthy commitment problem remains, with people with chronic disease, one of the biggest problems that faces those in charge of health, Because the World Health Organization indicate that, only about $50 \%$ of chronic patients in developed countries. A lower percentage of these patients in growing countries are committed to treatment. (Who, 2003).

Lack of the healthy commitment, for the chronic patients in general, and hepatitis patients in particular, one of the most important problems facing the therapists, and caretakers of these patients, this is because the disease has other aspects of psychological, social not only the biological aspect. Any perception of integrity, or what is known as bio-psychosocial model, which need to be examine the interrelationships between biological, psychological, and social factors, In the health and disease and the adoption of this model. we may find an explanation for the different levels of the healthy commitment, for Hepatitis $\mathrm{C}$ patients. This difference is due to several factors, including what is related to the disease, some of which is related to the treatment program, some of which is related to the patient, or any of personal factors. (Taylor, E Shelley., 2008).

From these factors sports exercise as a healthy lifestyle, which helps the individual to enjoy a good healthy life that may affect the patient's commitment to health instructions. All of this led to the attention of the researcher to identify the level of healthy commitment for Hepatitis virus (HCV) patient's athletes and nonathletes and find the differences between them.

\section{The research aim:}

The research aims to study the healthy commitment between athletes and non-athletes who Hepatitis virus (HCV) Patients by identifying: -

1- The level of healthy commitment for patients infected with hepatitis virus (HCV). 
2- The differences between the healthy commitment of athletes and nonathletes by hepatitis virus (HCV) patients.

\section{Research questions}

1- What is level of healthy commitment to the research sample of patients?

2- Are there differences in the healthy commitment between athletes and non-athletes patients of the research sample?

\section{Research procedures}

\section{Research Methodology:}

The suitable descriptive method to the nature of this research was selected.

\section{The research sample}

The research sample of (94) patients of HIV (C) were selected, (20) patient of them are exploratory sample, for the scientific processing of the questionnaire, Basic sample of (74) patients, of whom (40) patients exercising moderate physical activity, (34) patients are not practicing sport. All of them are undergoing treatment in Viral Hepatitis Center at Al Ahrar Hospital under the Ministry of Health in Zagazig, also they subjected to the supervision of medical hospital at Sidnawy Zagazig University by professors of the Faculty of Medicine University Who disclose these patients and follow-up of their health.

\section{Data collection tools}

The researcher used the following tools to gather data for this research that were as follows:

- The questionnaire of healthy commitment:-

The researcher has surveyed reference frame of the research, through references and research at the local level, and what it was got from the World Wide Web (Internet). So as to get the latest studies from international agencies. she has also met with doctors who specialize in the liver, gastrointestinal tract diseases, to Determine the main axes of Healthy commitment for patients who infected with hepatitis virus (HCV), The researcher has developed a number of (4) main points are: -

- Taking medicine.

- Medical follow-up.

- Diet system.

- Lifestyle.

- Instructions of questionnaire application:-

- The use of three-way balance of estimate (always sometimes - never) Represented in (3) always degrees - (2) sometimes degree - and never is one degree. Total score amounted to the questionnaire (87) degrees, Thus, the minimum and maximum research sample responses to the questionnaire are as follows:-

- (87) Maximum degrees

- (29) Minimum degrees.

- Took into account when formulating sentences to be some positive and others negative.

- Key of correction of plus phrases (3-2 - 1) and for minus phrases $(1-2-3)$.

\section{- The Basic study: -}

The researcher has applying the questionnaire on basic research sample at Zagazig town in Sharkeya Governorate in the period of $5-04 / 17 / 2016$.

\section{- Statistical treatments: -}


The data were statistically processed through the appropriate the data, which have been obtained and the purpose of achieving the objectives of the research, the

\section{First: presentation the Results: -}

Table (1) shows the Average total number to the axis of taking medications, statistical equations to the nature of

researcher used SPSS software version (9).

\section{Presentation and discussion of the results}

which amounts to (19.310). Which indicates a high level of research sample in the axis of taking medications.

Table (1) The level of Healthy commitment for the research sample at the center of taking medications. $(\mathrm{N}=74)$

\begin{tabular}{c|c|c|c}
\hline \hline Phrase No. & Phrase & Ranking \\
\hline \hline 1 & I bought my medicines before they implement the existing quantity & 2.525 & $(7)$ \\
\hline 5 & $\begin{array}{c}\text { Bring my medicines with me when traveling or during my absence } \\
\text { from home }\end{array}$ & 2.900 & $(3)$ \\
\hline 9 & Be sure to renew therapeutic insurance papers to ensure I got my \\
medication on time. & 2.400 & $(8)$ \\
\hline 13 & I do not take medicines because I believe that it hurt me more than it \\
would benefit me. & 2.675 & $(5)$ \\
\hline 17 & I take medication doses as prescribed by the doctor. & 3.000 & $(1)$ \\
\hline 21 & I take my medicines on time. & 2.925 & $(2)$ \\
\hline 24 & I stop taking medication when I feel better. & 2.700 & $(4)$ \\
\hline 27 & I forget taking my medicines & 2.675 & $(6)$ \\
\hline
\end{tabular}

Table (2) shows the Average total number for the axis of the medical follow-up, which amounts to (20.378), which indicates a high level of research sample at the center of medical follow-up.

Table (2) The level of Healthy commitment for the research sample at the center of medical follow-up $(\mathrm{N}=74)$

\begin{tabular}{c|c|c|c}
\hline \hline $\begin{array}{c}\text { Phrase } \\
\text { No. }\end{array}$ & Phrase & & Ranking \\
\hline \hline 2 & I make examinations regularly. & 2.297 & $(4)$ \\
\hline 6 & I consult my doctor when I feel that my health is up normal. & 2.445 & $(3)$ \\
\hline 10 & I remember the date of the doctor only when they feel tired. & 2.270 & $(5)$ \\
\hline 14 & I do not remember the date of visit to the doctor till medicines \\
run out & 2.554 & $(1)$ \\
\hline 18 & I commit to the dates of visiting a doctor. & 2.175 & $(8)$ \\
\hline 22 & $\begin{array}{c}\text { I analyzed the liver enzymes regularly to make sure the course } \\
\text { of treatment. }\end{array}$ & 2.527 & $(2)$ \\
\hline 25 & $\begin{array}{c}\text { I ask my doctor about my condition and the things that help to } \\
\text { improve the state of the liver and the things that I should stay } \\
\text { away to keep healthy. }\end{array}$ & 2.256 & $(6)$ \\
\hline 28 & I consult my doctor before taking any other medicine. & 2.229 & $(7)$ \\
\hline 29 & I use the notebook to record the analyzes. & 1.621 & $(9)$ \\
\hline & The total number of axis & 20.378 \\
\hline
\end{tabular}


Table (3) shows the average total number for the center of diet, which amounts to (10.635), which indicates a high level of research sample for the center of the diet.

Table (3)

The level of Healthy commitment for the research sample at the center of the diet.

$(\mathbf{N}=74)$

\begin{tabular}{c|c|c|c}
\hline \hline $\begin{array}{c}\text { Phrase } \\
\text { No. }\end{array}$ & Phrase & & Ranking \\
\hline \hline 3 & I eat fried food and spicy & 1.973 & $(3)$ \\
\hline 7 & I follow the special diet commensurate with the disease of C \\
virus (HCV). & 1.959 & $(4)$ \\
\hline 11 & I control myself in front of cuisine beyond diet. & 1.824 & $(5)$ \\
\hline 15 & I eat foods that contain iron. & 2.554 & $(1)$ \\
\hline 19 & I take juices more than eat fresh fruit. & 2.324 & $(2)$ \\
\hline \multicolumn{2}{c|}{ The total number of axis } & \multicolumn{2}{c}{10.635} \\
\hline
\end{tabular}

Table (4) shows the average total number to the axis of the lifestyle which is (14.486), which indicates a high level of the research sample at the center of lifestyle.

Table (4)

The level of Healthy commitment for the research sample at the center of a lifestyle

$$
\mathrm{N}=\mathbf{7 4}
$$

\begin{tabular}{c|c|c|c}
\hline \hline Phrase No. & Phrase & Ranking \\
\hline \hline 4 & I know my disease requires weak physical activity so I don't \\
exhaust myself too much & 2.297 & $(2)$ \\
\hline 8 & I drink coffee, tea and various types of stimulant drinks. & 2.040 & $(4)$ \\
\hline 12 & I smoke & 2.500 & $(1)$ \\
\hline 16 & I work on reducing my weight when increases. & 2.000 & $(5)$ \\
\hline 20 & I walk in order to improve my health. & 1.905 & $(6)$ \\
\hline 23 & I practice sport regularly. & 1.675 & $(7)$ \\
\hline 26 & I stay away from the pressure and tension. & 2.067 & $(3)$ \\
\hline \multicolumn{2}{|c|}{ The total number of axis } & 14.486 \\
\hline
\end{tabular}

Table (5) shows the average total number for the questionnaire of Healthy commitment, which amounts to (64.810), which indicates a high level of research sample in the total number to questionnaire of Healthy commitment.

Table (5)

The level of healthy commitment of the research sample.

$$
\mathrm{N}=74
$$

\begin{tabular}{c|c|c|c|c}
\hline \hline No. & Axis & & Ranking & Level \\
\hline \hline 1 & Taking medicine. & $\mathbf{1 9 . 3 1 0}$ & $(2)$ & High \\
\hline 2 & Medical follow-up. & $\mathbf{2 0 . 3 7 8}$ & $(1)$ & High \\
\hline 3 & Diet system. & $\mathbf{1 0 . 6 3 5}$ & $(4)$ & High \\
\hline 4 & Lifestyle. & \multicolumn{1}{|c|}{$\mathbf{6 4 . 8 1 0}$} & High \\
\hline 5 & Total questionnaire \\
\hline \hline
\end{tabular}


Table (6) shows there are differences with significant incorporeal, between athletes and non-athletes patients, in All axes of the questionnaire, and the total number is for the benefit of athletes patients.

Table (6)

Significance of differences between athletes and non-athletes in the extent of Healthy commitment. $\mathrm{N} 1+\mathrm{N} 2=74$

\begin{tabular}{c|c|c|c|c|c}
\hline \hline \multirow{2}{*}{ Axis } & \multicolumn{2}{|c|}{ Athletes } & \multicolumn{2}{c|}{ Non-athletes } & \multirow{2}{*}{$T$} \\
\cline { 2 - 6 } & Average & Deviation & Average & Deviation & \\
\hline \hline Taking medicine. & $\mathbf{2 1 . 8 0 0}$ & $\mathbf{9 3 9}$ & $\mathbf{1 6 . 2 2 5}$ & $\mathbf{3 . 7 0 1}$ & $\mathbf{8 . 9 3}$ \\
\hline Medical follow-up. & $\mathbf{2 3 . 8 2 5}$ & $\mathbf{2 . 5 8 0}$ & $\mathbf{1 6 . 3 2 3}$ & $\mathbf{4 . 3 3 2}$ & $\mathbf{9 . 2 0}$ \\
\hline Diet system. & $\mathbf{1 1 . 0 5 0}$ & $\mathbf{1 . 3 9 5}$ & $\mathbf{1 0 . 1 4 7}$ & $\mathbf{1 . 4 7 9}$ & $\mathbf{2 . 6 9}$ \\
\hline Lifestyle. & $\mathbf{1 6 . 2 2 5}$ & $\mathbf{2 . 0 4 4}$ & $\mathbf{1 2 . 4 4 1}$ & $\mathbf{1 . 7 2 6}$ & $\mathbf{8 . 5 1}$ \\
\hline Total questionnaire & $\mathbf{7 2 . 9 0 0}$ & $\mathbf{4 . 8 8 2}$ & $\mathbf{5 5 . 2 9 4}$ & $\mathbf{9 . 1 4 7}$ & $\mathbf{1 0 . 5 4}$ \\
\hline \hline
\end{tabular}

The tabulated $(\mathrm{T})$ value is $0.05=2.00$

\section{Second: Discussion the results: -}

- Focus of taking medications:

Table (1) shows the Average total number to the axis of taking medications, which amounts to (19.310), which indicates the sample's commitment to taking the medicine.

Where most of the studies have made the complexity of the regimen adversely effect on the healthy commitment, Both in terms of the number of doses, Or the complexity of the methods of use, or the intervention of several relationships at one time, the studies have shown that lack of commitment to the equivalent of $15 \%$ when treatment is limited to one medication and $25 \%$ when treatment consists of 2 to 3 medicines, $35 \%$ when up to more than 5 medicines. (Deblic, $\mathbf{j}$, 2007).

The researcher recalls to treat $\mathrm{HCV}$ is limited to two types of medicines, thereby increasing the patient's commitment to addressing medicines and dosages prescribed to speed his recovery.

\section{Focus of medical follow-up:}

Table (2) shows the results, the level of research sample, at the center of medical follow-up, which reached a high level with an average (20.378), Which indicates the commitment of sample in the medical follow-up.

Regime affects the healthy commitment and in this regard is noteworthy that, the lack of improvement in the symptoms suffered by the patient, the lack of noticeable therapeutic effect of treatment, that's the first factor to give it up, (Bauer, $\mathrm{C}$ and Tessier, $\mathrm{S}, \mathbf{2 0 0 1}$ ).

The patient is also very interested in the quality of the relationship it has with the doctor, However, there are some reservations carried by the patient on this relationship, whereas concentrated the directed criticism of the those who work in health care, usually about the low feedback, and use of specialized and complex scientific terms, sometimes the patient cannot understand, as well as the lack of focus of the doctor to the patient as a human being has distinctive character. (Taylor, E, 2008).

It is also the reasons for lack of healthy commitment of patients and their refusal to the treatment is the doctor no longer listen to the patient, in one study found that it, in $23 \%$ of the consulting patient cannot finish the symptoms and put his complaint to the doctor, even the doctor interferes to interrupt the patient before the end of his talk. In $69 \%$ of cases overall, the doctor interrupts the patient after twelve seconds 
of the beginning of patient's word, (Taylor , E, 2008).

Coll et Heedelberg mention that, $(39 \%)$ of patients only keep the continuation of therapeutic diet for three months after the end of the period of healing, Coll et Kruse adds, The study was based on computing census of the medicines, was conducted on 300 patients that are in hospital beds (51\%) of them have changed their medicine during the first ten days following their exit, And $(48 \%)$ have committed with less than half the medicines prescribed to them six weeks after the end of the healing, and Commitment ratio rises during periods of healing, due to permanent medical followup, (Bauer, $\mathrm{C}$ and Tessier, S, 2001).

World Health Organization report (2003), Referred to the quality of the relationship between the patient and the therapist, which would strengthen the compliance process for the treatment of the patient, and it must be seen to the patient on the basis that an effective party to the therapeutic process, the doctor must to involve the patient in the treatment plan, about choosing a diet, good nutrition system, which the patient will be subject to it, And the choice of therapeutic alternative methods, the disease and its symptoms and its complications in a simple way to explain in a manner, makes the patient knows more than his illness and that's what makes him more aware of his health condition, Making him more susceptible individual, to receive instructions from physician with acceptance. Which increases degree of healthy commitment he has, especially in patients with chronic diseases.

According to the researcher to the availability of medical follow-up, in patients with virus (HCV), Whether at the follow-up in Viral Hepatitis in Al Ahrar Hospital under the Ministry of Health in Zagazig town, which follow up pathological cases and give treatment, and through make the patients to conduct periodic analysis of each month, and Provide such analyzes to the center to determine the proper doses of therapy, and to be adjusted if necessary, then the need to conduct an interview with a specialist doctor, to explain the result of analysis and educating the patient with needed information to follow-up treatment, or whether the Sidnawy hospital in the university, through a group of professors of gastrointestinal in Faculty of Medicine. In order to renew their health insurance for the continued treatment exchange.

\section{- Focus of nutrition: -}

The table (3) results are the level of research sample in Focus of nutrition, which reached a high level and the average (10.635), which indicates the commitment of the research sample in nutrition.

Whereas the relationship between nutrition and liver reciprocal. Because everything we eat must pass after absorbed from the intestine to the liver, in addition, attention to nutrition, can memorize the liver in good health and, in many diseases of the liver, attention to nutrition takes special attention, Although the majority of chronic liver disease, especially cirrhotic accompanied by malnutrition, which in turn hinders the liver function tasks, And patients with liver disease need a diet rich in protein, carbohydrates, balanced amount of fat, vitamins, and minerals with the reduction of salt, which helps to maintain fluid in the body, So must be not to add to the food. (Abdul Rahman Althayedi, 2006).

The human health is affected by many interrelated factors, most important of which fresh air, lack of environmental pollution, and psychological and nervous relax. Many scientists also stressed that, Genetics and nutrition are main elements in the impact on human life. (Mohammed Al Ahamahmy, 2000).

Researcher Keeps in mind that, there is a clear eagerness of the research sample about, need to adhere to the food 
prescribed by the treating doctor, which confirms them through continuous followup sessions every month, which greatly affect the preservation of the liver's condition to be stable, and even help to speed recovery of the patient health status.

- Focus of lifestyle:-

Table (4) results are the level of research sample at the center of life style, that reached a high level with an average (14.486), which shows the commitment of the research sample in lifestyle.

Lifestyle is a pattern of behaviors and habits, which is characterized by the individual and can change the way of life, it is no longer consistent with the state of health or psychological, with the possibility of certain disorders, (Lutfi El-

\section{Sherbini, 2001).}

We emphasize that, the role of the psychological state of the patient, attention to ease nervous tension, anxiety for patients infected with the virus (HCV) and their families, because this stress weakens the immune system of the patient, which is responsible for defending the body, so reassure the patient and calm him down psychologically would increases the secretion of self-interferon, and thus increases the chances of responding to treatment. The patient is adhering to the hope of healing and believer in God, be his chance to respond more to the treatment of the patient depressed, (Abdul Rahman Althayedi, 2006).

We recall that the different variants of the patterns of life, such as getting used to relax, and visit scenic places that work on the palm of sight and nerves, and good relations with those around individuals, all variables can contribute to the prevention of diseases and promoted health, to achieve good health and enjoy better life, the individual can change his lifestyle, but it must be noted that it is not possible to change the genetics influencing factors in both fitness and health, (Mufti Hammad, 2010).

The physical exercise on a regular form, is one of the lifestyles that contribute to typical health, and to achieve effective life of society, and to improve the individual's dealt with the rest of its members, a high degree of efficiency.

The exercise helps to improve mood and lead to reduce stress, control of emotions, achieve psychological adjustment, (Hani Mohammed Hajar, Mahmoud Ismail, 2014).

The researcher stresses that, the keenness of a large number of research sample, a moderate exercise on a regular basis, such as walking has helped greatly in reducing tension and increasing mental health they have, which led greatly to the progress of treatment.

\section{Discussion}

Table (5) shows the existence of significant differences between athletes and non-athletes, in all axes of the questionnaire and the total number of it.

The researcher believes that, the fitness exercises contribute to the access to the high levels of health, that contributes to the prevention of diseases and promotes healthy commitment, practitioners individuals for sport that helps to improve the health level of the person, as the sport increases the opportunities for social interaction between individuals each other, which is a community group motivation the commitment of the patient's directives and orders of his illness, to speed healing and enjoy a normal life amidst other peers.

The exercise helps the patient to follow a healthy diet, and a commitment to diet prescribed by the treating physician, which helps significantly in treating the patient and the speed of his recovery.

Also sport exercising effect on the mental health of the patient, and working to reduce the sense of frustration, which results from the continued long-term 
treatment, no significant progress and improvement of the efficiency of the lifestyle and help to an improvement in the body's resistance to fatigue. (Mufti Hammad, 2010). Which means to improve the mood of the patient and increasing the commitment to follow healthy lifestyles, away from the tension and exercise, and away from the wrong habits, which contributes significantly to the improvement of the patient's condition.

\section{Conclusion}

1- Elevation the level of the healthy commitment of patients of research sample.

2- There are statistically significant differences in the healthy commitment, between athletes and non-athletes patients Hepatitis virus (HCV) for the benefit of the athletes patients.

\section{Recommendations}

1- Educate health providers to the importance of healthy commitment, and active role in increasing the healing rates for patients.

2- The need to provide patients with necessary information and recommendations for the disease, who suffer from it, and urged them to follow the recommendations needed to avoid the complications of the disease, and reduce the costs of treatment.

3- Carry out more in-depth studies aimed at increasing and improving the healthy commitment of the patients.

4- Do further researches about commitment among patients with various other diseases, and the impact of sports practice on it. 


\section{References}

1. Moftaah Mohamed Abdelaziz (2010): "Introduction to Psychology of Health", Amman, Jordan, Dar Wael Publishing, p. 60.

2. Abdul Rahman Alzayedi (2006): "Liver- integrated directory for liver disease - diagnosis treatment", Cairo, Dar Al Shorouk, p. 61-127.

3. Lutfi El-Sherbini (2001): "Encyclopedia of explanation, English/ Arabic psychological terminology ", Beirut, Arab Renaissance Publishing House, p. 359.

4. Mohammed Mohammed Ahamahmy (2000): "Nutrition and health for life and sport", Cairo, book publishing center, p. 54.

5. Mufti Ibrahim Hammad (2010): "Fitness for Health and Sports", Cairo, Dar al-Hadith book, p. 43-53.

6. Hany Mohamed Hagr , Mahmoud Ismail (2014): "Sport and Community Health", Cairo, the modern book publishing center, p. 56-63.

7- Bassuk, S., Manson, J. (2003): Physical activity and the prevention of cardiovascular disease. Curr Atheroscler Rep, 5: 299-307.

8- Bauer‘C،and Tessier ‘S. (2001 ) Observance thérapeutique chez les personnes âgées : Synthèse documentaire . Paris.pp, 17.

9- Colleen, A. et al. (2000).Health behaviour models. The International Electronic Journal of Health Education, 3, 180-193.

10-De blic . J (2007) .observance thérapeutique chez l'enfant asthmatique. Recommandations pour la pratique clinique revue générale . édition Elsevier. Masson .Paris.pp, 422.

11- Donna R. Falvo,(3rd edtion), (2005), Medical and psychological aspects of chronic illness and disability, USA, Jones and Bartlett Publishers, 17,21

12-Fletcher, G., Balady, G., Blair, S., Blumenthal, J., Caspersen, C., Chaitman, B., et al. (1996): Statement on exercise: Benefits and recommendations for physical activity programs for all Americans. Circulation, 94: 862- 867

13-Grundy, S., Blackburn, G., Higgins, M, et al. (1999): Physical activity in the prevention and treatment of obesity and itscomorbidities. Med Sci Sports Exerc, 31 (suppl): S 502- 508.

14- Hadigan C, Kottilil S. Hepatitis C, (2011): virus infection and coinfection with human immunodeficiency virus: challenges and advancements in management. JAMA ; 306: 294-301 doi:10.1001/jama.2011.975 pmid: 21771990

15-Haskell, W. (1994): Health consequences of physical activity: understanding and challenges regarding dose-response. Med Sci Sports Exerc, Vol. 26, p. 649-660 .

16- Pate, R., Pratt, M., Blair, S., Haskell, W., Macera, C., Bouchard, C., et al. (1995): Physical activity and public health. A recommendation from the Centers for Disease Control and Prevention and the American College of Sports Medicine. J Am Med Assoc, 273 (5): 402-407.

17- Pescatello, S., Franklin, B., Fagard, R., et al. (2004): American College of Sports Medicine Position Stand: Exercise and hypertension. Med Sci Sports Exerc, 36: 533-553. 
18- Pollock, M., Gaesser, G., Butcher, J., Despres, J., Dishman, R., Franklin, B., and Garber, C. (1998): ACSM Position Stand. The recommended quantity and quality of exercise for developing and maintaining cardiorespiratory and muscular fitness and flexibility in healthy adults. Med Sci Sports Exerc, 30: 975- 991.

19-Shepard CW, Finelli L, Alter MJ. Global epidemiology of hepatitis C virus infection. Lancet Infect Dis 2005; 5: 558-67 doi: 10.1016/S1473-3099(05)70216-4 pmid: 16122679.

20- Taylor, E . Shelley ( 2008 ) : Health psychology , sixth edition ,university of California , Los Angeles. Pp.64- 542.

21-Wild, S., King, H. et al. (2004). Global Prevalence of Diabetes: Estimates for the Year 2000 and Projection for 2030, Diabetes Care, 27, (5), 1047-1053.

22-world Health Organization, (2003): Adherence to long-term therapies:evidence for action, World Health Organization,Switzerland, ,P108.

23- http://www.who.int/bulletin/volumes/90/7/11-097147/ar/

24- http://www.who.int/mediacentre/factsheets/fs164/ar/ 